\title{
Objetos, cuerpos y memoria en el teatro argentino contemporáneo
}


OBJECTS, BODIES AND MEMORY IN CONTEMPORARY ARGENTINE THEATRE

\section{ABSTRACT}

In the 1990s, Argentine theater field is determined by the emergence of a heterogeneity of forms grouped by critics under the title "New Argentine Theater." These forms put in evidence the tension between an idealistic conception of the scene that had dominated independent theater until the 1980s and a materialist perspective that had developed surreptitiously in clear tension with the ways in which idealism conceive the relations between scene and history, subjects and objects, words and things but also in tension with the ways in which theater had thought itself as a memory device. In this context, El Periférico de Objetos arises and become stronger. I will analyze the production of this group, understanding that among the innovations it proposes from the manipulation procedure, is the exploration of objects and bodies as involuntary memory devices. With the aim of demonstrating that the productivity of the relationship between manipulation and memory is not limited to object theatre but also expands to dramaturgical production, I analyze two dramatic works that Daniel Veronese wrote in that same decade, in parallel to his activity as member of this group.

\section{Keywords}

inherited and found objects, manipulation and memory, contemporary Argentine theater, buried memory.

\section{RESUMEN}

En la década de 1990, el campo teatral argentino se encuentra determinado por la aparición de una heterogeneidad de formas agrupadas por la crítica bajo el título "Nuevo teatro argentino". Estas formas evidencian la tensión entre una concepción idealista de la escena que había dominado el teatro independiente hasta la década de 1980 y una perspectiva materialista que se había ido desarrollando subrepticiamente en tensión con los modos en que la primera planteaba las relaciones de la escena con la historia, de los sujetos con los objetos, de las palabras con las cosas y, como correlato, en tensión con el modo en el que el teatro se pensaba a sí mismo como dispositivo de memoria.

En ese contexto surge y se fortalece el Periférico de Objetos. Analizaré aquí la producción de este grupo entendiendo que entre las innovaciones que propone se encuentra la exploración, a partir del procedimiento de la manipulación, de objetos y cuerpos como dispositivos de memoria involuntaria. Con el objetivo de señalar que la productividad de la relación manipulación/memoria no se limita al teatro de objetos sino que se expande también a la producción dramatúrgica, analizo dos obras dramáticas que Daniel Veronese escribe en esa misma década, en paralelo a su actividad como integrante de este grupo.

\section{Palabras clave}

objetos heredados y encontrados, manipulación y memoria, teatro argentino contemporáneo, memoria enterrada. 


\section{INTRODUCCIÓN}

En 1990 la producción teatral argentina adopta una perspectiva distanciada respecto de los modos de llevar a la escena la historia argentina reciente, más específicamente en relación con los tópicos y temas asociados a la dictadura que el país había soportado entre los años 1976 y 1983. Esta distancia respecto de la intención de comunicar los acontecimientos traumáticos ocurridos hacía poco más de una década, fue leída especialmente como una falta de compromiso por parte de los artistas emergentes y como una actitud posmoderna de las nuevas generaciones. Sin embargo, subyace a este fenómeno de los años noventa un desplazamiento estético que se había iniciado en la década de 1970 , que fue interrumpido por la dictadura y que en los primeros años del regreso a la democracia se puso de manifiesto en los conflictos estéticos y políticos que sustentaron la oposición entre Teatro Abierto y el Under porteño (Dansilio, 2019: 138-155).

El Ciclo Teatro Abierto (CTA), en tanto propuesta estético política, había dado continuidad a un modo idealista de concebir la escena -y su relación con la historia- que era dominante desde 1930, año en el que el reconocido intelectual de izquierda Leónidas Barletta funda el Teatro del Pueblo ${ }^{1}$. La primera versión del CTA tiene lugar en 1981 y si bien se presenta como resistencia a la dictadura es sobre todo una respuesta a declaraciones de funcionarios referidas a la inexistencia del teatro argentino y a acciones como el cierre de la cátedra de Historia del Teatro Argentino en el Conservatorio Nacional de Arte Dramático. Frente a esa situación particular, veintiún autores y veintiún directores inician un ciclo de obras breves cuyo éxito supera rápidamente las expectativas de los organizadores. Roberto Cossa, Carlos Gorostiza, Griselda Gambaro, Ricardo Monti, Eduardo Pavlovsky y Carlos Somigliana son alguno de los autores; dirigen, entre otros, Omar Grasso, Jorge Petraglia, Carlos Gandolfo, Hugo Urquijo y Osvaldo Bonet, y suben a escena los actores más destacados del período. Apenas iniciada la programación, el Teatro del Picadero, sede de Teatro Abierto, es incendiado. Esto hace que intelectuales y artistas reaccionen en defensa del ciclo y los principales medios de comunicación -revistas opositoras como Humor, pero también los grandes diarios como Clarín y aun los más conservadores como La Nación- lo reivindiquen. Distintos dueños de salas ofrecen sus espacios y sus organizadores finalmente optan por continuarlo en el teatro Tabarís. De ahí en más, la gran afluencia de espectadores supera las expectativas iniciales. En su artículo sobre la recepción del CTA, Rodríguez y Lusnich citan entrevistas periodísticas en las que se destacan la palabra del público y las razones por las que acudían a las funciones del ciclo: "emocionarse", "verse representado", "identificarse", "participar" son algunas de las que explican la notoria concurrencia (2001: 221).

Son estos mismos motivos los que llevan al director Alberto Ure a cuestionar la complicidad entre público y espectáculo y la ausencia de una verdadera renovación estética. Para Alberto Ure, una de las primeras voces que critica el fenómeno Teatro Abierto, el público aplaudía "su propia existencia, su presencia, su intención de constituirse como público, su encuentro consigo mismo" en ese "verdadero melodrama de masas" que ofrecía al público "un soporte para los sueños que quiere soñar" para que ambos, público y espectáculo "se pierdan en la fascinación y la soledad" sin poner en juego otro pensamiento ya que "otro pensamiento resultaría intolerable" (2003: 221-226). Es notable que este "pacto idealista" entre realizadores y público que denuncia Ure sea el tópico involuntario de algunas de las obras más destacadas del ciclo. Por ejemplo, en El acompañamiento de Carlos Gorostiza, uno de los personajes, Sebastián, se solidariza con los sueños de cantor que tiene Tuco, el loco, y al final de la obra lo acompaña con 
una guitarra imaginaria. El mensaje optimista -soñemos a pesar de todo, nadie puede impedir que soñemos- y llamativamente idealista de la obra -la guitarra no es más que una ideatambién puede ser leído en términos de Ure: Sebastián -acompañante pero también público y Tuco -el artista soñador- terminan perdiéndose "en la fascinación y la soledad", en una réplica en pequeño de ese "melodrama de masas" que para Ure fue Teatro Abierto².

Lo cierto es que los modos de producción del CTA -como luego los criterios utilizados en los concursos de dramaturgia que servían de primera selección en las ediciones de los años posteriores- siguen la línea de una estética de lo comunicable, entendiendo lo comunicable como la herencia idealista del teatro independiente ${ }^{3}$ y como el valor canónico del teatro comprometido con la realidad social que se había ido naturalizando luego de una encendida polémica sobre el lugar social del teatro y del artista que se había dado a mediado de los sesenta entre realistas como Roberto Cossa y los neovanguardistas emergentes. Nos referimos a la polémica que se desata cuando la revista Thalía le entrega el premio a la mejor obra dramática de 1965 a El desatino, de Griselda Gambaro. Esta polémica está muy bien documentada por Osvaldo Pellettieri en Una Historia interrumpida (1996), y es el mismo Pellettieri quien señala el modo en el que esa polémica se termina resolviendo la década siguiente en un intercambio de procedimientos. Agrego a lo señalado por Pellettieri que el intercambio entre el realismo y la neovanguardia es posible porque, más allá de las diferencias procedimentales, ambas estéticas postulan una lógica escénica idealista sostenida por la identidad entre el fenómeno y la representación, por la causalidad directa o indirecta que siempre apunta a la continuidad y a la linealidad del mensaje y por la totalidad como garante del sentido de las partes. Cabe subrayar entonces que en el teatro argentino la intencionalidad y la referencialidad realista no son correlato de una concepción materialista de la escena.

Esa ausencia de una verdadera renovación estética en los años inmediatamente posteriores al proceso dictatorial, determinó que los acontecimientos de la historia reciente argentina fueran adquiriendo en la escena la forma y el peso de lo que Walter Benjamin (2012a), siguiendo una línea bergsoniana, llama "experiencia vivida". Parafraseando al filósofo resumo: la experiencia vivida está constituida por los acontecimientos que son incorporados al registro consciente como memoria voluntaria; por eso son plausibles de ser explicados en tanto contenidos de conciencia, pero no guardan para el presente nada de lo que ha sido la experiencia pasada a la que se refieren.

No obstante, si bien el modo idealista de acercarse a la historia reciente -representado por el ciclo Teatro Abierto- era dominante, operaba en la escena local, en tensión con este, una concepción materialista del lenguaje escénico que durante los años de la dictadura había logrado mantenerse subrepticiamente activa y que tenía a la dramaturgia de Ricardo Monti como principal exponente (Ferreyra, 2019). En esta concepción, que no solo permanece vigente sino que es hoy piedra de toque de la singularidad del teatro argentino, la relación entre la escena y la historia se encuentra apuntalada por contenidos de memoria involuntaria. La memoria involuntaria, como señala Benjamin retomando a Proust, trae al presente, de manera azarosa, los restos experienciales que la inteligencia no pudo asimilar como memoria voluntaria, restos a partir de los cuales la verdadera experiencia se constituye en imágenes. Benjamin neutraliza el carácter eminentemente privado que Proust le asigna a la verdadera experiencia contenida en el recuerdo involuntario al afirmar que: "Donde reina la experiencia en sentido estricto aparecen conjugados en la memoria ciertos contenidos del pasado individual junto con aquellos del pasado colectivo" (2012a: 190). 
En la verdadera experiencia los individuos obtienen una imagen histórico-social de sí mismos que es siempre precaria y que hay que reelaborar cada vez, puesto que se trata de una detención en la que el pasado individual entra en conjunción con el pasado colectivo. Por eso, para Benjamin, la verdadera experiencia es indisociable de la facultad humana de recordar, pues es en la memoria involuntaria que el sujeto se apropia de lo socialmente significativo (Weber, 2014: 491-494).

Ricardo Monti configura -en sus modos de plantear la relación de la escena con la historia, de los sujetos con los objetos y de las palabras con las cosas- una estética de lo inefable (Ferreyra, 2019) que en las décadas siguientes se consolidará en formas diversas ${ }^{4}$. Llamo estética de lo inefable al campo de tensiones que se abre en el desplazamiento de producciones idealistas hacia producciones materialistas. La estética de lo inefable cuestiona desde la escena a) la unidad de la conciencia, exhibiendo los restos de experiencia que han quedado fuera del alcance de esta; b) la trascendencia del símbolo, trabajando sobre la fragmentariedad perecedera de la alegoría; c) la progresividad de la historia, habilitando la detención necesaria para que el pasado individual y el pasado colectivo se conjuguen en imágenes. En este sentido, la estética de lo inefable podría ser abordada en relación con la controversia sobre la narrativa historiográfica y sus posibilidades en relación con el relato del trauma. Francisco Naishtat ubica el verdadero problema de este asunto en

el carácter de la disolución violenta y brutal de la experiencia que es propia del suceso traumático, como hecho ontológicamente imposibilitado de duelo, imposibilitado de organización narrativa bajo trama consoladora de atribución épica y de adscripción de acción y experiencia; imposibilitado, por ende, de la forma misma del sujeto de experiencia, del sujeto de acción y, en definitiva, de la identidad narrativa, que aquí, ante la catástrofe, oficiaría solamente, bajo la fórmula del "es war einmal", del "érase una vez", de máscara y autoengaño retóricos, a través de una tropología narrativa y una retórica aleccionadora y consoladora que ha quedado totalmente fuera de juego ante la fractura moderna del trauma histórico (2009:71).

Entonces, en el transcurso de la segunda mitad de la década de 1980, en evidente cuestionamiento a la estética de lo comunicable del CTA que, volviendo sobre la cita anterior, "oficia de máscara y autoengaño retóricos, a través de una tropología narrativa y una retórica aleccionadora", se fortalece la concepción materialista de la escena que había empezado a gestarse a principio de la década del setenta y que había permanecido latente durante los años de la dictadura en la obra de Ricardo Monti. Esta concepción puede reconocerse de manera fragmentaria en diversos proyectos dramatúrgicos pero también en las propuestas experimentales que inicialmente se dan a conocer en el marco del llamado circuito Under. Lo que me interesa subrayar aquí es que en esas nuevas propuestas escénicas las imágenes de la historia argentina reciente cuestionan y distancian las ideas sobre memoria y experiencia que se habían instalado y fortalecido a partir del Ciclo Teatro Abierto. De ese campo de tensiones del que participan cuerpos, objetos y palabras, surge la práctica de un grupo cuyas innovaciones estéticas y trayectorias de sus integrantes van a atravesar toda la producción escénica argentina de las décadas siguientes: el Periférico de Objetos $^{5}$.

La producción que el Periférico de Objetos desarrolla desde 1990 hasta su disolución ha sido ampliamente abordada (Propato, 2002; De Toro, 2005, 2006; Citlak, 2015), sin embargo, no han aparecido todavía investigaciones que profundicen la exploración estética que este 
grupo realiza sobre los cuerpos y objetos como dispositivos de memoria involuntaria, es decir, como dispositivos de recuperación de aquellos contenidos de experiencia individual y colectiva que no han sido procesados conscientemente pero permanecen en el presente adheridos a los cuerpos, los objetos, las palabras. En una primera parte de este artículo, me ocuparé de dar inicio a esa profundización prestando especial atención al procedimiento de la manipulación, que es el principio constructivo de las obras del Periférico de Objetos, y a su potencialidad para reconfigurar imágenes en las que, efectivamente, se recuperan contenidos de memoria involuntaria. En la práctica de la manipulación "el objeto real, físico, artificial, irracional, encontrado, construido, perturbado o interpretado es sometido a una acción, a un procedimiento frente al público, por un sujeto (su manipulador) que acciona sobre este objeto de tal modo que no es posible asegurar dónde termina uno y comienza el otro" (Alvarado, 2009: 47). El universo objetual del Periférico de Objetos, entonces, pone en crisis la creencia de que la conciencia puede abordar de manera autónoma el concepto de realidad y la realidad misma; se trata de un universo que pierde todo contacto con una idea de mundo organizadora del registro experiencial común.

Con la intención de evidenciar que a finales del siglo XX este modo de trabajar la relación entre escena, memoria y experiencia en el teatro argentino no se reduce a la consolidación del teatro de objetos sino que se encuentra en diálogo con nuevos modos de pensar la producción dramatúrgica, en una segunda parte voy a analizar dos textos dramáticos que Daniel Veronese escribe en paralelo a su actividad como integrante del Periférico de Objetos. En concordancia con los paradigmas de interpretación dominantes en los estudios teatrales de la década del noventa (Pellettieri, 2001; Dubatti, 2002), la dramaturgia de Veronese es considerada por buena parte de la crítica como la continuidad posmoderna del absurdo gambariano y como un ejemplo del canon de la multiplicidad que es consecuencia de un nuevo fundamento de valor asociado a ese mismo pensamiento posmoderno. De esta manera, entre los rasgos que la crítica releva como constitutivos de la escritura dramática de Veronese, aparecen apenas insinuados aquellos que remiten a su experiencia con el teatro de objetos. Los estudios sobre el teatro de este autor, entonces, pierden de vista lo que tempranamente se evidencia como la transposición de la relación manipulador-objeto -eje del teatro de objetos- a los términos de un lenguaje dramático. Para nosotros, lo que determina el carácter mecánico de la acción -la síntesis, la repetición y la obscenidad como condicionantes de la intriga, la ambigüedad de los personajes y la complejización del texto dramático- es el descubrimiento de las posibilidades expresivas de la manipulación en el momento de construir una teatralidad periférica en la que los contenidos de experiencia inscriptos en la memoria se emancipan de la conciencia como única puerta de acceso a un conocimiento respecto del pasado.

\section{El periférico de Objetos. Manipulación y memoria}

El Periférico de Objetos se da a conocer en 1990 con el estreno de Ubu rey ${ }^{6}$, una versión de la obra de Alfred Jarry. Si bien en este primer espectáculo el grupo se mantiene dentro de las convenciones del teatro de títeres, ya pone de manifiesto que la actividad del titiritero excede la construcción de universos maravillosos y el desarrollo de temáticas candorosas. En su segundo espectáculo, Variaciones sobre B... (1991), no quedan dudas de que el trabajo se orienta a la exploración de las posibilidades escénicas del objeto en relación con su manipulador. Si la idea era desplegar al máximo el potencial estético del objeto, se hacía necesario atender a que éste era indisociable del potencial expresivo del sujeto que lo manipulaba. 
El movimiento al que es sometido el objeto es lo que sugiere que lo que se ve es la "casi vida" del objeto ya que, obviamente, a pesar de ser capaz de accionar en la escena, su vida no es más que una proyección de la imaginación humana. Es un objeto queriendo ser un ser vivo, transformándose en personaje. Su papel es el de un ser vivo, pero limitado por la materia muerta que lo constituye. Es en esta contradicción en donde reside su encanto, en ese lugar donde entran en contacto la materia y el espíritu. (Alvarado, 2009: 43).

Los materiales básicos que comienzan a poblar la escena del Periférico de Objetos -los muñecos mutilados, los artefactos caducos, el vestuario quirúrgico- funcionan como materia prima de imágenes que cuestionan los modos establecidos de concebir la relación sujeto/objeto no solo como dinámica escénica sino también como forma de conocimiento del mundo y como registro histórico.

\subsection{La latencia histórica de los objetos}

Inmerso entonces en un proceso de asimilación estético-política del pasado reciente que en las artes escénicas, como señalamos más arriba, tuvo su punto de giro en Teatro Abierto, y en interacción con el movimiento cultural under que se desarrolla a lo largo de la década del ochenta, el teatro de objetos se ofrece, entre otras cosas, como una nueva matriz de memoria. A diferencia de las propuestas que siguen la línea de Teatro Abierto, en las que la escena funciona como una metáfora de experiencias pasadas con la que se garantiza la identificación emotiva del espectador bienpensante, el Periférico complejiza la acción de recordar recuperando la latencia histórica de los objetos.

Esto es posible porque la manipulación recorta al objeto de su contexto original y lo inserta en una composición nueva que transforma su manera de significar y los significados asociados a ella, incluidos aquellos que determinan su temporalidad. La escena se presenta como una nueva forma de conocimiento que surge del "insano equilibrio" que las cosas adquieren en un nuevo montaje. Por eso, para dar sentido escénico a un muñeco, o a una abrochadora, o a una camilla, al espectador -como al manipulador -no le alcanza con buscar en la memoria las posibles articulaciones de éste con otros en un contexto que le era propio, tampoco le alcanza con descubrir al objeto completamente desprendido de las funciones y usos que lo anclaban a una habitación infantil, o a una oficina, o a un quirófano. El sentido surge precariamente en la conjunción del pasado y del presente en las cosas. El objeto se activa como dispositivo de memoria a partir del choque entre los restos de experiencias que trae almacenados y la historicidad material de la composición escénica.

El hombre de arena (1992) es quizás el espectáculo que, paradójicamente, en su oscuridad muestra nítidamente esta operación. Allí el relato de E.T.A Hoffman se escenifica desde lo más insignificante, desde lo más obsceno y degradado: una caja llena de tierra y unos muñecos a los que le falta la "tapa de la cabeza"7. La práctica de la manipulación hace de la inercia y el movimiento los extremos de un único mecanismo que escapa a cualquier racionalización y que es a un tiempo vital y fúnebre. Esto es así porque en su composición la escena libera a los objetos de su ordenamiento consciente: la caja llena de tierra remite a una tumba pero también al arenero de una plaza; en las viudas -interpretadas por los manipuladores -se entrelazan imágenes de duelo y de juegos infantiles; los muñecos muestran las dos caras que señala Lotman: "una atrae al mundo acogedor de la infancia, la otra se asocia con la pseudovida, el movimiento muerto, 
la muerte que se finge vida" (Lotman, 2000: 99-100). El gesto de superación de la muerte, es decir la vida, está contenido y se libera en los cuerpos inertes de los muñecos animados por la manipulación. Al mismo tiempo, en la reiteración compulsiva de sus acciones, las viudas se cosifican, se vuelven artefactos de un hacer automático cada vez más veloz.

La crítica, y probablemente también el público, vio en El hombre de arena la representación de los acontecimientos más oscuros de la historia argentina reciente: la desaparición de personas, el asesinato masivo, el entierro en fosas comunes. Imposible eludir esa visión. Sin embargo, es conveniente señalar que el trabajo del Periférico de Objetos no se agota en esa representación; se propone además como alternativa al modo idealista de vincularse con el mundo de las cosas, aquel que considera que su verdad se reduce a la conciencia que tenemos de ellas. Los espectáculos del grupo revisan esta consideración habilitando la hipótesis de que la manipulación les permite configurar en imágenes un contenido de experiencia acumulado en la memoria de los objetos.

Esta hipótesis funciona con el supuesto de que existe en las cosas un saber respecto del pasado que se encuentra por afuera del procesamiento consciente a la espera de un lenguaje que lo traduzca en imágenes. Apoyado en este supuesto, el grupo polemiza a un tiempo con el teatro de títeres y con el teatro de actores en tanto ambos desestiman a los objetos como dispositivos de memoria a favor de un sujeto que recuerda y toma consciencia de lo acontecido. En alguna medida, la memoria de los objetos recupera para el recuerdo aquello que la toma de consciencia descarta por no ser funcional a una determinada idea de mundo consensuada a espaldas de las cosas y los sentidos cifrados en ellas. En las formas obsoletas de los artefactos, en los mecanismos gastados de los aparatos a cuerda, en el antropomorfismo anticuado de los muñecos, permanecen latentes imágenes que guardan algo de lo que verdaderamente ha sido ese pasado, más allá de las ideas que la mirada subjetiva haya desarrollado para darles sentido.

En las imágenes opacas e inexplicables que la manipulación configura en la escena -cirujas ciegos que transforman acciones amorosas en actos de tortura, viudas que desentierran y entierran cuerpos inertes-, la historia se muestra en lo que tiene de dolorosa y fallida. La escena periférica opera como memoria de la historia reciente manipulando en la precariedad del presente contenidos residuales de experiencia que escapan a la conceptualización y perviven en muñecos mutilados, en caducos sillones de dentista o en anteojos anticuados, y se transfieren al cuerpo de quienes manipulan y a la voz de quienes narran; somete a objetos, cuerpos y textos a una mirada microscópica capaz de ver el contenido de verdad que perdura en lo marginal, lo insignificante, lo limítrofe.

\subsection{La subjetividad corrompida por los objetos}

El procedimiento de la manipulación funda así un territorio poético en el que los personajes son reducidos a un estado criatural, a una subjetividad cosificada. A partir de su segundo espectáculo el Periférico de Objetos se orienta de lleno a la exploración de ese nuevo territorio creado por la manipulación. En él el sentido elude la coincidencia del objeto con la idea que de él tiene el sujeto, se ubica en el punto exacto en el que esa coincidencia es negada: 
nivel de ese rango de vida). El individuo beckettiano - del mismo modo que en nuestro proceso de manipulación- parece no poder discernir dónde termina su cuerpo y dónde empieza realmente su objeto. Los objetos, entonces, funcionando como verdaderas prótesis. Hay perversión en esos objetos que permiten comunicar y examinar el mundo: bicicletas, bolsos, valijas, paraguas, sillas de rueda, mecedoras, escaleras. Cambio de su funcionalidad permanente. Cosificación material del sujeto. Cosificación de los personajes (Veronese, 1999/2000).

En efecto, en Variaciones sobre B... el universo beckettiano es empujado desde el planteo de lo absurdo de la existencia hacia la exploración del objeto en el sujeto e investiga los modos en los que el muñeco en tanto producto histórico cultural opera como modelo para una existencia degradada a la objetualidad.

De ahí en más el sujeto de la escena periférica oscila entre su transformación en cadáver o en mercancía a partir de imágenes que delatan algunas de las formas inefables que asume la existencia cuando se la percibe en su constante caída hacia lo inerte. Al funcionar como "prótesis" de los objetos, el cuerpo del manipulador habilita la posibilidad de que estos se sustraigan al despotismo de la subjetividad humana para dejar de ser meros transmisores de contenidos dados y mostrarse como productores de nuevos sentidos. Estos nuevos sentidos que provienen de configuraciones escénicas montadas a partir de esos restos materiales de un pasado común llevan a una reformulación de los conceptos de experiencia y de conciencia.

Promediando la primera presidencia de Carlos Menem en Argentina ${ }^{8}$, cuando algunos valores que sostenían la primavera democrática empiezan a mostrarse como materia histórica fracasada, el sistema estético que el Periférico de Objetos desarrolla refiere de manera crítica los modos en los que el teatro argentino piensa su relación con la historia y la política argentinas. Critica principalmente una escena "comprometida" en la que predominan los contenidos de conciencia por sobre los contenidos de experiencia. En oposición a esto, el Periférico de Objeto sale a "cazar" imágenes que condensen restos de experiencia vinculados inexorablemente a la decadencia y a la muerte. En la indagación de un territorio poético que se presente como alternativo al desarrollo simbólico del teatro predominantemente idealista, los espectáculos del grupo descubren forman posibles para un saber histórico vedado a la comunicación consciente.

Los objetos manipulados traen a la escena contenidos de memoria que en efecto remiten a la historia reciente del país pero lo hacen desde un contenido experiencial periférico a la consciencia. En este sentido son memoria involuntaria en la que se hacen presentes de manera azarosa aquellas experiencias que la inteligencia no pudo asimilar como memoria voluntaria, por ejemplo, la relación entre el éxito del mercado y la caída de lo humano en lo objetual y la operatividad de la reducción de los sujetos a objetos antropomórficos en una lógica capitalista. La necesidad de desplazar la percepción del espectador desde una subjetividad social idealizada -condensada en la figura del artista comprometido -hacia una subjetividad corrompida por los objetos se vuelve el modo estético de recuperación de un orden de experiencia menospreciado: el de los objetos.

Rescatados del basurero cultural, los muñecos y sus accesorios se ofrecen como humanidad mortificada en un presente signado por la transitoriedad. Transitoriedad no como sinónimo de deshistorización sino como forma alternativa al orden causal. Transitoriedad como la forma histórica que guarda en la potencia expresiva de las ruinas lo que efectivamente ha sido. 
Así, en Cámara Gesel/ ${ }^{9}$ (1994) la transitoriedad funciona como emblema del deseo materialmente sometido al mundo objetual. Los muñecos y la actriz autómata no son meras copias humanas, sino que operan, al igual que las máquinas de la era industrial, como modelos de una existencia potencial que evoca en la materia inerte los deseos de belleza, de modernidad y de progreso no desde su trascendencia sino desde su fracaso. La búsqueda individual de Tomás, el protagonista de Cámara Gesell, de la "cálida escena familiar" que lo contenga y lo defina, tiene su correlato en la búsqueda colectiva de la "cálida escena democrática" en la que se cierren las viejas heridas y en la que reine la paz del mercado.

Para el teatro de objetos, que empieza a tener un lugar destacado en la cartelera teatral independiente, la historia argentina, al igual que la historia de Tomás, no es otra cosa que una acumulación desordenada de cuerpos, textos y objetos a cuya materialidad se encuentran adheridas tanto las aspiraciones libertarias como las aspiraciones fascistas del "sujeto apto para desear" -con esta expresión se presenta al personaje en la primera escena. La vida de Tomás se expone en una serie de cuadros que muestran su precario equilibrio de "sujeto deseante". El niño se desplaza entre dos campos de fuerza: uno externo, en el que operan los gestos que animan la vida social y otro interno, que lo arrastra hacia la inercia propia de los objetos. No se trata entonces de entender al personaje como metáfora de la sociedad argentina -a la manera de Teatro Abierto- sino de desentrañar los mecanismos de un sistema objetual, asimilable a la familia, asimilable al mercado, que subyace tanto al deseo individual como al deseo colectivo. Mecanismos que hacen de la experiencia un punto ciego cuya verdad -oculta tras el orden causal que nos hace conscientes de nuestra historia -se alcanza a vislumbrar cuando ya es demasiado tarde.

\subsection{La mirada alegórica}

El teatro de objetos entonces es ejemplo de uno de los desplazamientos más interesantes que operan en el campo teatral de Buenos Aires de fines de siglo XX: la producción escénica empieza a cuestionar abiertamente la mirada simbólica con la que se identifica al teatro histórico y político, practicando una mirada alegórica ${ }^{10}$. Para Benjamin (2012: 208-209), la alegoría, en oposición al símbolo, está directamente asociada al procesamiento temporal y al desarrollo de un modo de percepción que acerque al observador a experiencias en las que el pasado sea presencia transitoria antes que consciencia trascendente; un modo de percepción de la historia como "historia del sufrimiento del mundo". Se trata de una temporalidad poética asociada a la decadencia y el martirio, en donde cobra especial importancia la expresión de una dialéctica continua entre lo animado y lo inerte, entre lo vivo y lo muerto. En los espectáculos del Periférico de Objetos el sujeto le pelea su protagonismo a los objetos y junto con ellos a su cadáver. A diferencia del símbolo, el modo alegórico "permite volver visiblemente palpable la experiencia de un mundo fragmentado, en el que el pasaje del tiempo no significa progreso sino desintegración" (Buck-Morss, 1995: 36). Así, los cuatro espectáculos que el Periférico de Objetos produce desde 1995 hasta el 2000 ilustran el derrotero de este punto de vista alegórico en torno al sujeto y su contexto que tiene a la latencia histórica y a la corrupción de la subjetividad como principios.

Máquina Hamlet, el texto de Heiner Müller escrito en 1977 y estrenado en Alemania en 1988, asume desde el principio un modo de expresión alegórico que muestra la historia de Europa y la propia biografía del autor en tanto subjetividad corrompida por los objetos. Que Müller tome de su maestro Bertolt Brecht fundamentalmente este carácter lo prueba la forma en la que 
el mismo define su modo de producir: "Mi interés principal cuando escribo teatro es destruir cosas" (Müller, 1996: 159). Que ese carácter destructivo de la dramaturgia de Müller pueda asociarse a lo que Benjamin define como un modo de expresión alegórico, está sintetizado en el impulso de "reducir las cosas a su esqueleto, arrancándole la carne y la superficie" (Müller, 1996: 159). Se trata una vez más de la expresión de lo que se extingue; el esqueleto no es tanto la estructura sino el despojo de un mundo en proceso de putrefacción. El esqueleto de Hamlet deambula por la costa, delante de las ruinas de Europa. Se cruza con el cortejo fúnebre que acompaña al cuerpo del padre muerto. Abre el Ataúd y reparte los restos entre los miserables. El féretro vacío sirve de lecho amoroso al asesino y a la viuda. Hamlet, símbolo del hombre moderno, percibe el mundo en su putrefacción. Podemos decir que la obra se inicia con el emblema de la modernidad europea. En la construcción de ese emblema, Müller utiliza elementos fragmentarios de la alegoría barroca: el esqueleto, la ruina, el féretro, el cuerpo desmembrado, la putrefacción. Es evidente que, como en los emblemas y Trauerspiele que analiza Benjamin (2012), aquí también el acontecer histórico se imprime en la materialidad caída.

Para entender en toda su dimensión el lugar que Máquina Hamlet ${ }^{11}$ ocupa en la producción del Periférico de Objetos, es necesario señalar que en el trabajo que el grupo realiza sobre la dramaturgia de Müller opera la misma lógica de destrucción/construcción que anima la poética del autor alemán ${ }^{12}$. Los integrantes del Periférico de Objeto buscan las correspondencias con su realidad en los detalles actuales y propios que surgen de la fragmentación del texto de Müller en imágenes que dislocan los modos racionales de la relación sujeto/objeto. El trabajo creativo se orienta a encontrar una imagen -no una idea -en el aquí y ahora de la Argentina de los noventa para la inscripción emblemática que surge de la lectura "destructiva" del texto dramático. La voz en off del espectáculo cita al texto de Müller en lo que este tiene de actual: la modernidad argentina cita a la modernidad europea en tanto materia histórica fracasada.

En la puesta en escena periférica de Máquina Hamlet, la dialéctica de lo animado y lo inerte opera como dinámica de la experiencia de los sujetos en la historia, experiencia que se expande a partir de la utilización de muñecos antropomórficos que duplican el cuerpo y el rostro de los actores-manipuladores en tanto gestos. En la configuración del personaje trágico los maniquíes y los actores se alternan para representar la vida y la muerte sin solución de continuidad: Hamlet en tanto emblema de la modernidad es exhibido en su caída hacia lo inerte, lo que aparece a la vista es un universo rígido e inseguro signado por la percepción de una identidad siempre transitoria. En la interacción entre los muñecos y sus manipuladores, como en las calaveras animadas de los emblemas barrocos, se hace dialécticamente visible que si a lo inerte se lo despoja de su quietud y a lo animado de su movimiento nos encontramos frente a "lo otro" en tanto "lo mismo". De eso se trata Máquina Hamlet, de la búsqueda de imágenes que expresen la dimensión objetual de la existencia humana. Así, apuntan sus críticas directamente al conocimiento subjetivo del mundo; a fuerza de manipulación hacen de la escena el lugar en el que se descubre otro modo de conocimiento que no tiene como garantía ni al entendimiento del sujeto ni a la identidad del objeto con su concepto, un conocimiento que reconoce en el objeto un "otro" y un "mismo".

En este sentido, Maquina Hamlet resiste el constructo memorístico racional que predomina en las miradas sobre el pasado reciente de la Argentina y propone un modo de recordar desde los objetos. Recordar desde los objetos permite traer a la escena el pasado reciente en tanto saber aún no consciente de lo que ha sido esa experiencia. Ese saber fragmentado y residual 
se encuentra en los objetos y hacia ellos dirige el Periférico de Objetos la mirada alegórica del espectador. En este sentido, la poética del grupo sostiene que hay en ellos una verdad de la experiencia que por inestable e incierta no puede ser expresada en un concepto o idea. Esto que parecería funcionar como límite es en realidad el origen de las imágenes periféricas. Susan Buck-Morss, refiriéndose a Benjamin, asocia este modo de conocimiento a un antropomorfismo que se asimila al modo de producción del Periférico de Objetos:

Describir los fenómenos como si tuvieran vida propia, como si expresaran una verdad acerca de la cual su creador humano no fue consciente, constituía un rasgo único de los escritos de Benjamin. Era una suerte de antropomorfismo, una expresión moderna de lo arcaico, que también aparecía en los escritos de Adorno. Pero en lugar de sustraer a la naturaleza de su otredad identificándola con el sujeto, este antropomorfismo tenía el efecto inverso de incrementar la no identidad, la extrañeza del objeto. Benjamin llamaba "aura" a esa extrañeza y constituía un tema místico en sus escritos (2011: 191).

Este rasgo que Buck-Morss define en la escritura de Benjamin -en sintonía nada menos que con la noción de "aura" - puede relacionarse con una mirada alegórica que funda una nueva forma de relación del sujeto con las cosas que lo rodean. De este modo, El Periférico de Objetos le propone al espectador "una mirada más allá de lo convenido" que le proporcione "un sentido más profundo que la realidad conocida del objeto, que su simple representación" (Veronese, 2000: 312).

Después de tres años de exitosas giras con Máquina Hamlet, el Periférico de Objetos presenta Zooedipous (1998), espectáculo en el que "decide abordar un material escénico tradicional, Edipo, con toda libertad y encararlo, más por los autores que reflexionaban en esos años sobre el mito que por la tragedia en sí, y usar ese material teórico según lo que éste les sugería escénicamente, como si fuera un texto dramático" (Alvarado, 2013: 11). Es evidente que en este espectáculo el grupo intenta volver sobre la fórmula de Máquina Hamlet: armar una imagen del presente con los fragmentos de un producto cultural enraizado. En este proyecto, el filósofo argentino Tomás Abraham funciona como una suerte de dramaturgista que les presenta algunas lecturas que, a finales del siglo $\mathrm{XX}$, se vinculan con la tragedia. El principal referente de la propuesta de Abraham es el Antiedipo de Gilles Deleuze y Felix Guattari. Si en Máquina Hamlet el carácter destructivo era el punto de partida necesario para la construcción de un estado de cosas suspendido en la dialéctica de lo animado y de lo inerte, en Zooedipus el pensamiento deconstructivo será el camino metodológico para la producción de un espectáculo en el que predominan la desterritorialización y la descorporalización como formas de la existencia humana. A diferencia de Máquina Hamlet, Zooedipus es deliberadamente posmoderna en cuanto prescinde de la materialidad de los restos para centrarse en la disolución de los materiales.

Es notable que el espectáculo con el que cierran la década del noventa, Monteverdi Método Bélico (2000) -donde vuelven a trabajar con el dramaturgista alemán Dieter Welke -tenga como principio el establecimiento de una relación entre la perspectiva deconstructiva que desarrollan en Zooedipous y el universo de la alegoría barroca que funciona como imaginario en Máquina Hamlet y que, en alguna medida, estructura la autorreferencialidad de Circonegro, el espectáculo que media entre ellos. Este interés por poner en relación el emblema barroco -una forma artística que está en el origen de la modernidad -con la maquinaria posmoderna constituye una síntesis del recorrido estético del grupo y el punto desde el que comienza a 
perfilarse el devenir estético de sus integrantes. Es la obra del Periférico de Objetos en la que la constante caída en la objetualidad se enfrenta a los esfuerzos de los cuerpos posmodernos por sustraerse a ella: "Es ese resto de cuerpo no siliconado el único que da cuenta de la finitud, del paso del tiempo. De la vida y de su posibilidad de reproducirse. Muy entrenado, marcado, operado, buscando la eterna juventud del cuerpo, buscando ser máquina perfecta de la escena, aún lo humano sobrevive en él. En su deseo absoluto de ser otro, de ser reconocido detrás de ese otro. Lo humano, lo carnal de la escena es el actor mismo y no su personaje" (Alvarado, 2011: 12).

Si se presta atención al derrotero experimental del Periférico de Objetos se puede comprender cabalmente el lugar que ocupa en la configuración de la escena argentina contemporánea. No solo fue el puntapié para el desarrollo y consolidación del teatro de objetos en nuestro país, también abrió la puerta a nuevas formas de concebir las relaciones entre lo animado y lo inerte en la escena al reconocer la latencia histórica que habita en las cosas y fundar en ella su valor como dispositivos de memoria, al desdeñar la subjetividad como consciencia de lo que fue y centrarse en el momento en que esta es corrompida por los restos objetuales del pasado y al propiciar una mirada alegórica que renueva el acto de recordar desde la materialidad fracasada de los objetos.

\title{
3 La dramaturgia de Daniel Veronese: un saber aún no consciente de lo que ha sido
}

En la década de 1990, en paralelo a su actividad con el Periférico de Objetos, Daniel Veronese comienza a desarrollar su carrera de dramaturgo. Las primeras obras que da a conocer evidencian su interés por el absurdo, algo que la producción del grupo ya había mostrado. Sin embargo, su singularidad radica en el desplazamiento hacia la escritura dramática del procedimiento de manipulación, propio de la práctica del teatro de objetos. En ese desplazamiento también es posible observar que Veronese piensa su escritura como matriz de memoria para la historia reciente en consonancia con su trabajo en el Periférico de Objetos.

Ahondar en una existencia materialmente corrompida es la finalidad que, desde el inicio, se intuye en el teatro veronesiano. Por eso es necesario observar que si, al igual que el absurdo, la dramaturgia de Veronese disuelve al personaje, lo hace para reconfigurarlo en cuanto subjetividad modelada por los objetos. En este sentido, se advierte en los personajes la fuerza del no-ser-ya con la que Benjamin caracteriza los pasajes de París:

\begin{abstract}
Haber pasado, no ser ya, es algo que actúa apasionadamente en todas las cosas. A ello le confía el historiador su asunto. Se apoya en esa fuerza y conoce las cosas como ellas son para un instante del no-ser-ya. Monumentos tales de un no ser ya, son los pasajes. Y la fuerza que actúa en ellos es la dialéctica. La dialéctica los revuelve, los revoluciona, hace de lo superior lo inferior, convirtiéndolos, dado que no quedó nada de lo que son, de lugares de lujo en (X). Y nada de ellos permanece sino el nombre: pasajes, y: pasaje $d u$ Panorama. En lo más íntimo de estos nombres actúa la subversión, por eso conservamos un mundo en los nombres de las calles antiguas, y leer por la noche el nombre de una calle equivale a una transmigración (?) (Benjamin citado en Hillach, 2014: 659).
\end{abstract}

Los personajes de Veronese se encuentran como los pasajes parisinos que observa Benjamin en el instante de no-ser-ya y, como ellos, se expresan en imágenes de inquietud petrificada. En la detención dialéctica de los extremos de la existencia, los rasgos del sujeto moderno son 
revueltos, revolucionados, subvertidos: este se transforma frente al espectador en una "cosa pasada de moda" $y$, al igual que los pasajes, solo conserva de su existencia anterior el nombre que, en efecto, funciona como significante que cristaliza la lucha entre lo vivo y lo petrificado. En sus primeras obras, Veronese descubre que expresar artísticamente "nuestra mitología íntima" implica atravesar la existencia idealista que la conciencia subjetiva construye y alcanzar la "existencia corrompida" que las formas "demasiado estables" ocultan. La manipulación es el principio que le confiere imprecisión a esas formas, poniendo en duda "los principios indubitables del arte" (2000: 315).

En consonancia con esto, cuando propone en el segundo de sus Automandamientos "promover un principio de sustitución de los actores vivos por objetos" (2000: 309), está remitiendo a una práctica enraizada en la cultura: la utilización de objetos antropomórficos rígidos o con movimientos automáticos que, en determinados ámbitos socioculturales como el juego, la moda, la propaganda, el arte, sirven de modelo a la existencia humana. Veronese destaca en esta sustitución de lo animado por lo inerte manipulado la apertura de una dimensión que no tiene referencialidad en nuestra vida cotidiana (2000: 309), una dimensión que se hace visible cuando los sujetos adquieren una perspectiva objetual: cuando es el humano el que imita la existencia del objeto. Obviamente, con esto Veronese no pretende transformar el teatro de actores en teatro de objetos, sino explorar un modo de expresión artística asimilable al que en el teatro de objetos tiene el actor-no-manipulador que "es en apariencia muy superior en expresividad y movilidad a cualquier objeto, no obstante, puede llegar a verse inseguro e imperfecto frente a la contundencia del objeto" (Alvarado, 2009: 45-46).

Por este fondo de experimentación dramaturgia es que no se puede reducir la complejidad de la dramaturgia veronesiana a una determinación mecanicista que "representa la incomunicación, la despersonalización y el silenciamiento brutal al que fue sometida la sociedad desde el golpe de estado de 1976" y en la que "la palabra visibiliza la cruel realidad" (Fobbio, 2010: 12). $\mathrm{Si}$, en efecto, el teatro de Veronese remite a la historia reciente, no lo hace ejercitando la memoria voluntaria de los sujetos sociales - denunciando la experiencia vivida-, sino apelando a la activación de la memoria involuntaria depositada en los objetos. Los monologuistas de Veronese, en obras como Señoritas porteñas, Luisa y Luz de mañana en un traje marrón, exhiben de manera obscena la suspensión de su humanidad en los objetos: están siempre haciendo pie en la frágil frontera que separa el cuerpo de la cosa, y el monólogo es la dimensión discursiva de esa frágil frontera que la imagen de inquietud petrificada resume.

En Formas de hablar de las madres de los mineros mientras esperan que sus hijos salgan a la superficie y en Equívoca fuga de señorita apretando un pañuelo de encaje sobre su pecho, dos obras escritas en 1994, la memoria es indisociable de la reconstrucción de un saber respecto del pasado reciente de la Argentina que aún no se ha hecho consciente y que tiene en la objetualidad su territorio.

En la primera de estas obras, Isabel se encuentra en una oficina incierta -conectada con la entrada de la mina en la que desde hace doce años trabaja su hijo-con una finalidad más incierta aún. Allí la atienden el Hombre y la Secretaria, figuras que, utilizando accesorios como bigotes, sombreros o pelucas, asumirán distintos roles frente a Isabel. Tales accesorios funcionan como "prótesis" que sirven a un juego permanente de reemplazo de un personaje por otro, análogo al que se produce en Cámara Gesell. En efecto, "Ios actores vivos" que deberían encarnar a los distintos personajes son sustituidos por "objetos" cuyas posibilidades expresivas están 
orientadas a producir una significación siempre inestable, siempre en los bordes o en las grietas de lo conocido o esperado: lo que aparece a la vista es un universo rígido e inseguro signado por la percepción de algo que se presenta como provisorio. La credulidad de Isabel frente al burdo accionar sustitutivo del Hombre y la Secretaria no solo descubre la actitud negadora de la sociedad argentina frente a los acontecimientos de la dictadura (Dubatti, 2006: 20), muestra además las limitaciones que tiene el juicio subjetivo como forma de acceder a la verdad. Isabel es funcional a la ilusión en la que el lenguaje convencional-expresión de la conciencia subjetivatiene atrapadas las cosas. Lo que se le presenta al espectador como sentido es eso que Isabel no puede asimilar, ese resto de experiencia que proviene de la tensión entre las fuerzas de lo animado y las fuerzas de lo inerte, una zona análoga al despertar y a la memoria involuntaria proustiana.

La escena, entonces, no es la metáfora de la experiencia vivida en el pasado reciente, sino la imagen de un saber aún no consciente de lo que ha sido esa experiencia (Benjamin, 2013: 875). Ese saber sobre el pasado que no ha sido procesado subjetivamente se encuentra en los objetos, y hacia ellos -hacia la materialidad insignificante y transitoria de un bigote, de un sombrero o de un par de guantes- orienta Veronese la mirada de Isabel, y, con ella, la del lector/espectador. De esta forma, su dramaturgia sostiene que hay en esos objetos una verdad que por inestable e incierta no puede ser expresada en un concepto o idea. Al igual que en la dramaturgia montiana, y en consonancia con la producción dramática que surge en los noventa, la escritura de Veronese tiende hacia las imágenes que, lejos de asumir los rasgos de una realidad idealizada, la rebajan a lo que tiene de fallido y de transitorio. Como en la contemplación alegórica del Periférico de Objetos, en las obras de Veronese "el mundo profano se eleva de rango, al mismo tiempo que se lo devalúa" (Benjamin, 2012: 218). En su escritura se condensa un contenido difícil de justificar desde los principios idealistas, porque en ella "la adecuación de pensamiento y ser como totalidad... se ha descompuesto" (Adorno en BuckMorss, 2013: 178).

En Equívoca fuga de señorita apretando un pañuelo de encaje sobre su pecho, mientras los padres, los amigos y el cartero se disputan la verdadera versión respecto de la desaparición de Martina, la intriga queda suspendida en el saber "aún no consciente" de lo que ha ocurrido con ella y es en el sostenimiento dramático de esa suspensión que el conflicto de la obra se transforma en el emblema de ese saber.

La primera parte se detiene en la rememoración que los padres de Martina hacen de la cotidianeidad con su hija. En la superficie del diálogo, plagado de lugares comunes sobre el amor filial, se reconstruyen parodiados valores familiares convencionales:

Madre. ¿No pudiste darte cuenta de que esto iba a pasar?

Padre. Dormía. Estaba descansando como todas las noches.

Madre. No, como todas las noches no. Seguro que ayer no descansaba.

Padre. Parecía soñar con ángeles.

Madre. No era con ángeles con lo que soñaba. Soñaba seguramente con un oscuro camino que la alejaba de todo lo conocido, de su familia. Aunque nos parezca increíble, su mente ya estaba preparando la fuga mientras todo parecía estar en su sitio. ¿Su ropita 
ya colgaba de la percha?

Padre. Querida, sabés que...

Madre. (interrumpiéndolo) Contestá. ¿Le llevaste el vaso de agua? ¿Lo pusiste sobre su mesita de luz, lo tapaste con la carpetita gris de lino? Contestá.

Padre. Sí, sí, lo hice.

Madre. (Pausa) Ese es el sitio en que deben estar las cosas en esta casa, cuando todo está en orden.

Padre. ¿Entonces? No podemos sentirnos culpables.

Madre. (Pausa) No. (Veronese, 1997: 234-235).

Lo que se rememora adquiere una dinámica asimilable al absurdo de las obras de Griselda Gambaro, sobre todo en lo que se refiere a la parodia de las relaciones sociales y a la mirada irónica sobre el imaginario colectivo. Sin embargo, el estatuto que adquieren la parodia y la ironía es el de ser formulaciones absurdas de la experiencia vivida, es decir, de aquellos contenidos de existencia procesados conscientemente como garantía de que "todo está en orden".

La percepción involuntaria de lo que ha sido se manifiesta, en cambio, en la observación de lo que subyace de manera periférica a la reconstrucción memorística de la armónica escena matinal, cuando esta es atravesada por "una mirada más allá de lo convenido", que proporciona "un sentido más profundo que la realidad conocida del objeto, que su simple representación" (Veronese, 2000: 312):

Padre. Entonces, papito, me levanto y voy corriendo a besarla (Pausa). Y lo hacía. (Pausa). ¿O no? Si me parece estar viéndola. (Pausa.) ¿O no éramos nosotros tres, esos seres embriagados de felicidad que se sentaban alrededor de esta mesa, estirando los brazos...?

Madre. (Sonriendo.) Sí, ¿te acordás? Los estirábamos para alcanzarnos, parecía que se nos iban a despegar del cuerpo de la alegría.

Madre. Sí... (Pausa.) Y después un beso grande para el padre.

Padre. Sí. Después, sí, un beso al padre, pero solo si había necesidad, si quedaba tiempo, si no nada...nada, yo no me hacía problema por eso.

Madre. Mi amor... ¿tenías celos?

Padre. ¿Qué decís? Ver esa escena matinal era mi mayor anhelo. ¿Cuál podía ser el mayor deleite para un padre como yo? Yo era un camino entre ustedes, era un mensajero. Quien las contenía. Tanto amor entre madre e hija necesitaba un dique, una contención, yo era quien las protegía, quien...

Madre. (Interrumpiéndolo, quebrándose) Está bien, está bien, por favor. Un poco de piedad. 
Padre. Pero no estoy mintiendo, no, de ninguna manera.

Madre. No... ya lo sé.

Padre. ¿Y entonces...? De ahora en más quiero que los dos la recordemos prefiriendo a la madre, antes que al padre.

Madre. Vení aquí. Ya entendí. (Él se acerca para que ella lo bese). Sos muy bueno conmigo.

Padre. Estoy seguro que vos también quisiste serlo con ella.

Madre. (Pausa.) Nos quería a los dos. ¿Está bien?

Padre. (Sonriendo tristemente) Nos quiso a los dos por igual, si así lo querés. Está bien. Así debió ser en una casa como la nuestra y así la recordaremos (Veronese, 1997: 236237).

La mirada que va más allá de lo convenido se detiene en el funcionamiento automático de los componentes de la escena matinal -"entonces, papito, me levanto y voy corriendo a besarla"y en la modalidad desiderativa que predomina en la configuración de esa escena: "¿O no éramos nosotros tres, esos seres embriagados de felicidad que se sentaban alrededor de esta mesa, estirando los brazos...?", "Está bien. Así debió ser en una casa como la nuestra y así la recordaremos". La obra no propone entonces una representación simbólica de las relaciones históricas de poder, sino imágenes alegóricas de experiencias asociadas a las representaciones del poder. Estas circulan en las dinámicas familiares como en las dinámicas histórico-políticas en tanto conjunción de contenidos de experiencias pasadas y presentes.

En la zona limítrofe entre el sueño y la vigilia en la que Veronese ubica sus obras, las imágenes fijan la relación dialéctica entre lo animado y lo inerte como un modo de recuperar desde la memoria involuntaria los restos de experiencias que permanecen por fuera del dominio de la conciencia: en sus obras estos se configuran artísticamente como la existencia humana penetrada por el mundo de las cosas, y es esto lo que hace que las imágenes, en rigor irreales, se perciban cargadas de contenido histórico.

\section{CONCLUSIONES}

La irrupción de los objetos en el teatro argentino y de la práctica escénica de la manipulación vuelve en los años noventa sobre el problema del conocimiento de la historia. La producción del Periférico de Objetos cuestiona especialmente la relación transparente que se establecía, en las formas más estables de la escena local, entre la conciencia reflexiva y la existencia del objeto; y lo hace explorando la latencia histórica de muñecos mutilados y artefactos caducos, trabajando sobre imágenes que aprovechen la potencia expresiva de una subjetividad atravesada por lo inerte, y habilitando formas alegóricas de la memoria. Frente a la predominancia de una escena que se presenta como resistencia al pasado reciente, se consolida esta otra que niega, fragmenta y discontinua el pasado para exhibirlo al servicio de una reconfiguración de la experiencia sensible en el presente.

Por esos años la escena teatral empieza a verse cada vez más como el campo dialéctico en el que el símbolo y la alegoría pugnan por tener el dominio de la temporalidad. A diferencia del 
símbolo, el modo alegórico "permite volver visiblemente palpable la experiencia de un mundo fragmentado, en el que el pasaje del tiempo no significa progreso sino desintegración" (BuckMorss, 1995: 36). Es en ese campo de tensiones donde la propuesta del Periférico de Objetos y su resonancia en la dramaturgia de Daniel Veronese resultan tan significativas para estudiar la relación entre teatro contemporáneo, memoria e historia reciente.

En uno y otro caso, y en consonancia con la estética de lo inefable como base conceptual, la mirada respecto de la historia es una mirada distanciada, asimilable a la que Walter Benjamin le adjudica al historiador materialista: la mirada del alegorista que no ve en la historia una sucesión de hechos homogéneamente ordenados en su devenir hacia el progreso, sino un salto dialéctico que permite pensarla en su transitoriedad. En ese salto dialéctico, la memoria involuntaria se activa para recuperar en imágenes discontinuas, fragmentarias, negativas, la verdadera experiencia: ese saber aún no consciente de lo que ha sido, que permanece inexorablemente adherido a los objetos, a los cuerpos y a los discursos.

\section{REFERENCIAS}

Alvarado, A. (2009). "El objeto de las vanguardias del siglo XX en el teatro argentino de la Postdictadura. Caso testigo: El Periférico de Objetos" en Dubatti, J. (Comp.). Escritos sobre teatro II.

Buenos Aires: Nueva Generación. 11-80.

Alvarado, A. (2011). "La maquinaria barroca". Topología de la crítica teatral II. Buenos Aires: Ediciones IUNA-Dramáticas. 9-12.

Alvarado, A. (2013). "Zooedipus". Topología de la crítica teatral III. Buenos Aires: Ediciones IUNA-Dramáticas. 9-13.

Benjamin, W. (2013). Libro de los pasajes. Madrid: Akal.

Benjamin, W. (2012a). El París de Baudelaire. Buenos Aires:

Eterna Cadencia, 2012.

Benjamin, W. (2012b) Origen del Trauerspiel alemán. Buenos Aires: Gorla, 2012.

Buck-Morss, S. (2011). Origen de la dialéctica negativa. Theodor W. Adorno, Walter Benjamin y el Instituto de Frankfurt. Buenos Aires: Eterna Cadencia.

Buck-Morss, S. (1995). Dialéctica de la mirada. Walter Benjamin y el proyecto de los Pasajes. Madrid: Visor.

Cytlak, K. (2015). “Objetos molestos en escena. Comentarios sobre la recepción del concepto de objeto en el teatro de Tadeusz Kantor por elPeriférico de Objetos" en Telón de fondo $\mathrm{N}^{\circ}$ 21. 
Dansilio, F. (2019). “Entre Teatro Abierto y el under porteño. Conflictos estéticos y políticos del teatro independiente durante la transición argentina" en Contemporánea. Historia y problemas del siglo XX, pp. 138-155, Año 10, Volumen 10.

De la Puente, M. (2011). “Arte y terror. Nombrar el horror desde el teatro". En Giordano, Carlos et al. (eds), Cuestiones sobre comunicación, arte y estética, pp. 42-55. Buenos Aires: EPC.

De Toro, A. (2005). "El Periférico de Objetos. Topografías de la hibridez: cuerpo y medialidad" en Gestos N 40, pp. 13-41.

De Toro, A. (2006). “El Periférico de Objetos, II: prácticas de corporalización y descorporalización” en Gestos N41, pp. 13-40.

Dubatti, J. (2001). "Introducción" en Dubatti, J. (Compilador). EI nuevo teatro de Buenos Aires en la postdictadura (1983-2001), pp. 3-72. Buenos Aires: Centro Cultural de la Cooperación.

Dubatti, J. (2006). "La dramaturgia de Daniel Veronese: Poéticas y lecturas". En Cuerpo de prueba II, pp. 9-39. Buenos Aires: Atuel.

Ferreyra, S. (2019). Estética de lo inefable. Hacia una genealogía materialista del teatro argentino. Los Polvorines: UNGS.

Fobbio, L. (2010). “Daniel Veronese y el monólogo dramático de postdictadura: interacciones conflictivas, taxidermia de formas, una voz colectiva". En VV. AA., Actas de las Primeras Jornadas de Investigación y Crítica Teatral pp. 1-18. Buenos Aires: Asociación Argentina de Investigación y Crítica Teatral.

Hillach, A. (2014). "Imagen dialéctica". En Opitz, Michael y Wizisla, Erdmut, Conceptos de Walter Benjamin, pp. 644-708. Buenos Aires: Las Cuarenta.

Lotman, I. (2000). "Los muñecos en el sistema de la cultura" en La semiosfera III. Semiótica de las Artes y de la Cultura. Madrid: Frónesis/Cátedra/Universitat de Valencia. 97-102.

Müller, H. (1996). Germania: muerte en Berlín y otros textos. Navarra: ArgitaletxeHiru.

Naishtat, F. (2009). "Refocalización historiográfica y cambio de régimen de historicidad" en Espacios controversiales. Hacia un modelo de cambio científico y filosófico, pp. 53-86. Buenos Aires: Miño y Dávila. 
Pellettieri, O. (1997). Una historia interrumplida. Buenos Aires: Galerna.

Pellettieri, O. (2001). Historia del Teatro Argentino en Buenos Aires. El teatro actual (1976-1998). Buenos Aires: Galerna.

Pellettieri, O. (2006). Teatro del Pueblo: una utopía concretada. Buenos Aires: Galerna.

Propatto, C. (2002). “El Periférico de Objetos: resignificación político histórica y distanciación objetual" en Dubatti, J. (Compilador). El nuevo teatro de Buenos Aires en la postdictadura (1983-2001). Buenos Aires: Centro Cultural de la Cooperación.

Pucciarelli, A (coord.) (2011). Los años de Menem. La construcción del orden neoliberal. Buenos Aires: Siglo XXI.

Rodríguez, M. y Lusnich, A. (2001). “La recepción del teatro de Arte" en Pellettieri, O. (director). Historia del Teatro Argentino en Buenos Aires. El teatro actual (1976-1998). Buenos Aires:

Galerna.

Ure, A (2003). "El doble juego de público y actores" en Sacate la careta. Ensayos sobre teatro, política y cultura. Buenos Aires: Norma.

Veronese, D. (2000). “Automandamientos" en La deriva. Buenos Aires: Adriana Hidalgo. 309-315.

Veronese, D. (1999/2000). El Periférico de Objetos. Recuperado de http://www.autores.org.ar/dveronese/periferico.htm

Veronese, D. (1997). "Señoritas porteñas". En Cuerpo de prueba, pp. 141-151. Buenos Aires: UBA.

Veronese, D. (1997). "Luisa”. En Cuerpo de prueba, pp. 153-163. Buenos Aires: UBA.

Veronese, D. (1997). “Luz de mañana en un traje marrón”. En Cuerpo de prueba, pp. 165-179. Buenos Aires: UBA.

Veronese, D. (1997). "Formas de hablar de las madres de los mineros, mientras esperan que sus hijos salgan a la superficie". En Cuerpo de prueba, pp. 193-229. Buenos Aires: UBA.

Veronese, D. (1997). "Equívoca fuga de señorita apretando un pañuelo de encaje sobre su pecho". En Cuerpo de prueba, pp. 


\section{2-261. Buenos Aires: UBA.}

Weber, T. (2014) “Experiencia”. En Opitz, Michael y Wizisla, Erdmut, Conceptos de Walter Benjamin, pp. 644-708. Buenos Aires: Las Cuarenta. 479-525.

\section{NOTAS}

1. El teatro del Pueblo y su trayectoria serán referencia insoslayable para el movimiento del Teatro Independiente de Buenos Aires (Pellettieri, 2006). Aquí no interesa señalar su importancia para la configuración a nivel nacional de una idea de proyecto artístico cultural comprometido con las luchas del pueblo.

2. En la página del archivo de la Televisión Pública Argentina se pueden ver online versiones para televisión de las obras que integraron la primera versión del ciclo Teatro Abierto, entre ellas El acompañamiento: https://www.tvpublica.com.ar/programa/teatro-abierto/

3. Nos referimos al carácter idealista de una imagen (representación) cuyo valor de verdad es subalterno de un concepto de conocimiento entendido como la identidad entre la conciencia subjetiva y la experiencia objetiva (Pellettieri, 1997:110). El punto de partida de la imagen escénica es una idea de mundo que la precede y legitima.

4. El llamado "Nuevo teatro argentino" y sus derivas no pueden analizarse de manera profunda si no se entiende el impacto que la producción montiana tuvo en los jóvenes productores que constituyeron ese fenómeno.

5. Grupo de experimentación escénica, asociada específicamente al desarrollo del teatro de objetos, fundando en 1989 por Ana Alvarado, Daniel Veronese, Emilio García Wehbi y Paula Nátoli, todos integrantes del Grupo de Titiriteros del Teatro General San Martín. En sus más de quince años de actividad se fueron sumando, de manera estable o provisoria, otros integrantes como Román Lamas y Alejandro Tantanian. En el desarrollo de este artículo haremos un recorrido por la mayor parte de su producción.

6. Los espectáculos del Periférico de Objetos son presentados como producciones colectivas, más allá de los textos que incorporan como material en el proceso de producción.

7. En la página web de Emilio García Wehbi, integrante fundador del Periférico de Objeto, se pueden consultar imágenes de este y otros espectáculos del grupo que ilustran estas afirmaciones: http://emiliogarciawehbi.com.ar/archivo/el-hombre-de-arena/

8. Carlos Menem fue presidente de Argentina desde 1989 a 1999, su gobierno se caracterizó por políticas de evidente corte neoliberal que desembocaron en 2001 en una de las crisis sociales y económicas más duras de la historia del país. Para una profundización sobre las características de su presidencia se puede consultar el volumen Los años de Menem, Construcción del orden neoliberal, coordinado por Alfredo Pucciarelli (2011).

9. Actualmente se encuentra en la plataforma YouTube un registro audiovisual de este 
espectáculo: https://www.youtube.com/watch?v=5KdVglq2ql0\&t=1463s

10. No solo en el desarrollo del teatro de objetos se puede verificar esta tensión, también en el teatro que realiza Ricardo Bartís a partir de Postales argentinas (1989) y en la "nueva dramaturgia" que empieza a producirse en los años noventa, sobre todo en torno al colectivo de autores autodenominados Caraja-jí.

11. En la plataforma YouTube pueden rastrearse fragmentos de registro audiovisual de este espectáculo. Por ejemplo en https://www.youtube.com/watch?v=5IOr13Xd6OE

12. "La idea fue partir del texto de Müller, tratar de entenderlo y desglosarlo en una suerte de listado de unidades mínimas. El texto quedó dividido entonces en cuarenta unidades. Esas unidades estaban dadas por un eje temático. A cada unidad le asignamos un título. Una vez hecho esto, traspasábamos esas unidades a ciertas imágenes que tuvieran que ver con la realidad argentina. El proceso de montaje decantó así en una suerte de listado de una determinada cantidad de imágenes que aludían al título de cada una de las unidades, a los ejes temáticos de las mismas y por ende a ciertas zonas del texto" (Tantanian citado en De la puente, 2011: 44-45). 